\title{
Surgical Reduction of Symphysis Fracture and Sponta- neous Repositioning of the Mandibular Condyle: A Case Report
}

\author{
Danilo Azevedo Ramos, ${ }^{1}$ Nestor Estéfano de Oliveira, ${ }^{2}$ Claudemir de Carvalho ${ }^{3 *}$ \\ ${ }^{1}$ Dentist, University Center FUNVIC, Pindamonhangaba-SP, Brazil \\ ${ }^{2}$ Maxillofacial Surgery and Traumatology, Regional Hospital of Vale do Paraiba, Brazil \\ ${ }^{3}$ Dean of Research and Graduate Studies, University Center FUNVIC, Brazil
}

\begin{abstract}
The condylar process is a more fragile area, which is usually fractured by indirect trauma. The objective of this study is to report the case of a 10-year-old patient who presented to the Maxillofacial Surgery and Traumatology Service of the Regional Hospital of Vale do Paraíba, in Taubaté-SP, Brazil. Physical examination revealed limited mandibular movement with painful symptoms, crossbite, and upper incisor avulsion. A face tomography showed a fracture of the mandibular symphysis (right side) and a fracture of the left condyle. Surgical reduction of the mandibular symphysis fracture was performed. After exposure and reduction of bone segments, maxillomandibular block, rigid internal fixation and conservative treatment for condyle fracture were performed. A soft liquid diet and weekly outpatient follow-up was adopted for the first two months. After 15 days of surgery, the patient had mild edema, slight limitation in mouth opening, sutures without dehiscence and without signs of infection. In the first control tomography, the treated fracture was adequately reduced and the fractured condyle remained with medial displacement in the glenoid cavity. After one year, on physical examination, the patient presented satisfactory dental occlusion, preserved mandibular movements and no signs of nerve damage. The tomography showed the fracture consolidated, and the left mandibular condyle well positioned in the glenoid cavity. After two years, the third tomography was performed, showing remodelling of the left mandibular condyle.
\end{abstract}

Keywords: Mandibular fracture, Condylar fracture, Symphysis fracture, Spontaneous condyle repositioning

\section{Introduction}

Mandibular fractures are among the most common types of fractures in trauma involving the face, ranking second among the bones of the maxillofacial skeleton. ${ }^{1-3}$ Facial fractures in pediatric patients occur mostly in the age group above five years. Regarding the etiology, the causes are similar to those of facial fractures in adults. Children older than 5 years usually suffer from traumas of greater energy, such as those caused by car accidents, sports activities and falling from a bicycle. ${ }^{4}$ Due to the particularities of this type of trauma, the form of treatment has been widely discussed, especially in pediatric patients due to the still incomplete bone growth..$^{5-7}$
Although some latest studies have shown open method of treatment results in better functional outcomes, consensus regarding the preferred mode of treatment of mandibular condylar fractures is lacking among clinicians. ${ }^{2}$ Functional treatment is inspired by physiological principles, where the condyles are stimulated by the action of the masticatory muscles, especially the lateral pterygoid, guiding bone repair and remodelling, as described in the functional matrix theory of MOSS and in the principle of apposition and resorption Wolff's bone. ${ }^{8}$ The objective of this paper is to report a case of spontaneous repositioning of fractured mandibular condyle in an adolescent submitted to symphysis surgery after a fall from a bicycle.

\begin{tabular}{|l|l|}
\hline \hline Quick Response Code: & *Corresponding author: Claudemir de Carvalho, Research and Graduate Studies, University \\
Center FUNVIC, Estrada Radialista Percy Lacerda 1000, CEP 12412-825, Pindamonhangaba, \\
SP, Brazil \\
Received: 20 July, 2021 \\
Citation: Ramos DA, Oliveira NE, Carvalho C. Surgical Reduction of Symphysis Fracture and \\
Spontaneous Repositioning of the Mandibular Condyle: A Case Report. SOJ Den Oral Disor.
\end{tabular}




\section{Case Report}

In view of ethical aspects, the responsible for the patient signed the Informed Consent Term agreeing with the publication of the case, provided that the patient's anonymity was maintained. A 10-year-old female patient, victim of a bicycle fall, presented to the Oral and Maxillofacial Surgery and Traumatology Service of the Regional Hospital of Vale do Paraíba, in Taubaté-SP, Brazil, complaining of pain and difficulty in opening the mouth. During anamnesis, there was paresthesia in the mental region, normal vital signs and absence of systemic diseases. On physical examination, limitation of opening, closing, laterality, protrusion and retrusion of the mandible was observed, with painful symptoms, crossbite, and avulsion of the upper incisors. A fracture of the mandibular symphysis and a high fracture of the right condyle with medial displacement were found (Figure 1).

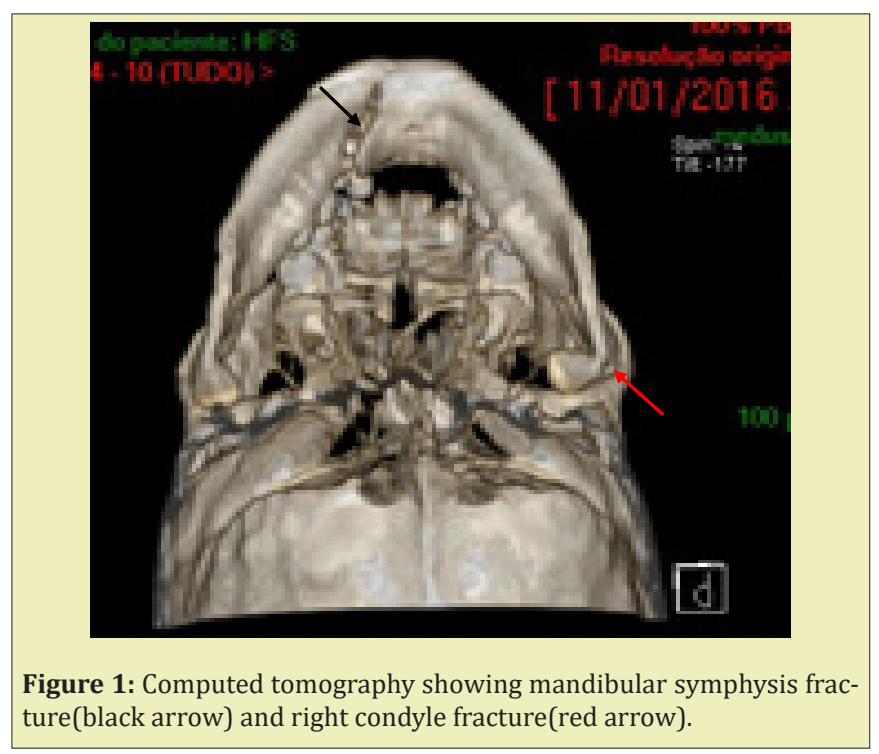

Condylar fractures must be managed according to the clinical and case presentation. ${ }^{9}$ In this specific case, because there was no sliding of the condyle into the middle cranial fossa, no extracapsular displacement of the condyle, no presence of a foreign body inside the articular capsule, nor mechanical obstruction preventing the function of the temporomandibular joint, ${ }^{10}$ we opted for conservative treatment. Surgical reduction of the mandibular symphysis fracture under general anaesthesia and nasotracheal intubation was proposed. ${ }^{11}$ Anterior mandibular vestibule surgical approaches were performed. After exposure and reduction of the bone segments, a maxillomandibular block was performed using locking screws and a No.1 steel wire and rigid internal fixation performed with two $2.0 \mathrm{~mm}$ miniplates of the $2.0 \mathrm{~mm}$ system (Figure 2). For the high fracture of the left condyle with medial deviation, conservative treatment was chosen, considering the patient's age. Elastic therapy was instituted in addition to a soft-liquid diet and weekly outpatient follow-up during the first two months. Postoperatively, there was mild edema, slight limitation in mouth opening, no signs of infection, and no suture dehiscence.

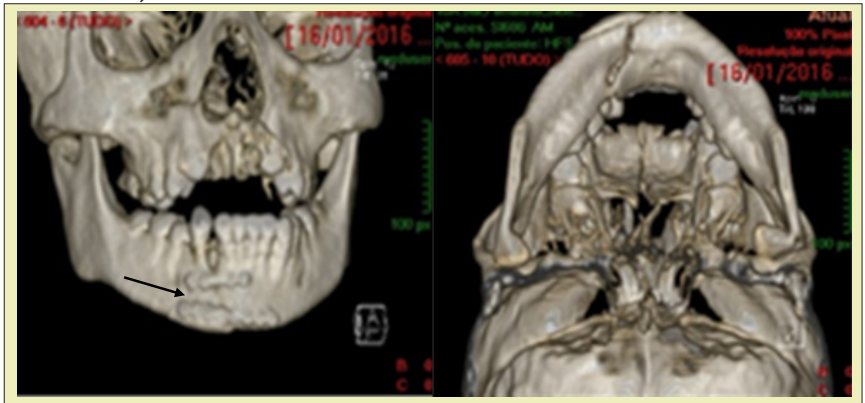

Figure 2: Osteosynthesis with plates and screws (black arrow) in mandibular symphysis fracture and conservative treatment of the right condyle.

After one year of outpatient follow-up, on physical examination, the patient presented satisfactory dental occlusion, preserved mandibular movements and no signs of nerve damage. At control computed tomography, the treated fracture was consolidated and the right mandibular condyle was well positioned in the glenoid cavity (Figure 3). After two years, a new control tomography was performed, showing a remodelled and well-positioned right mandibular condyle in the glenoid cavity (Figure 4).

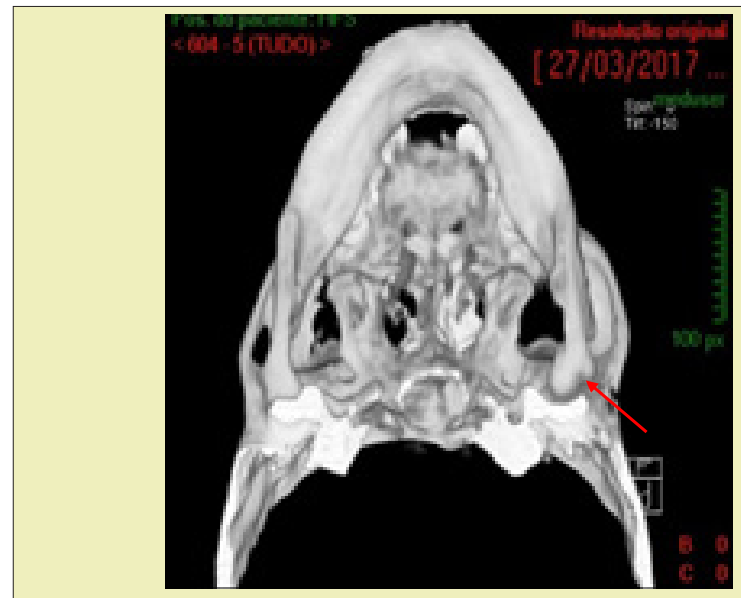

Figure 3: Control tomography after one year showing the spontaneous repositioning of the right condyle (red arrow).

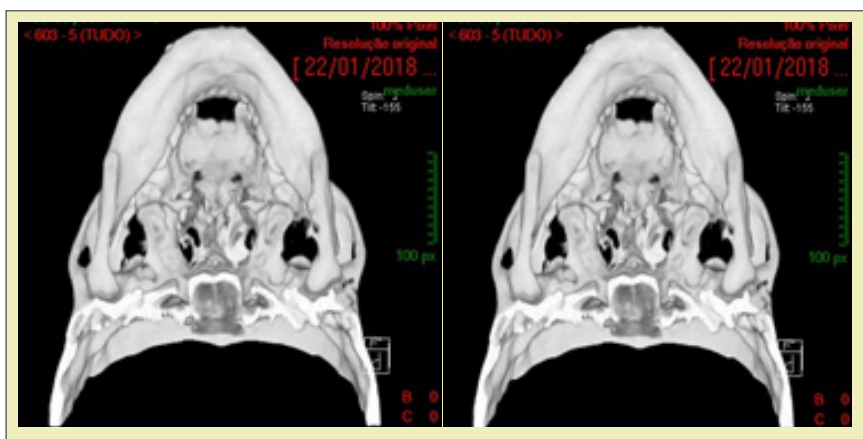

Figure 4: Control tomography two years after treatment showing there modeled and well positioned right mandibular condyle. 


\section{Discussion and Conclusion}

The treatment of mandibular condyle fractures has been a matter of considerable controversy for years mainly in relation to open reduction or conservative treatment. Condyle fractures must be treated according to the particularity of each case, always evaluating the risks and benefits of each intervention. ${ }^{1,2,12}$ It should be considered that the access for surgical reduction of condyle fractures is performed in the region where important anatomical structures are present, such as the facial nerve, internal maxillary artery, facial artery, temporal artery and parotic gland, making access in this region more difficult due to the risk of injury to these structures. ${ }^{13}$ Some aspects of the treatment of condylar fractures remain controversial, the conservative method or closed reduction is chosen when there is no dislocation, or in children younger than 12 years, due to remodelling of the mandibular condyle. ${ }^{9,10}$

The most conservative and functional approach is aimed at maxillomandibular block, early speech therapy, the use of elastics and release daily for a soft-liquid diet, allow early mobilization of the joint, in order to prevent future ankylosis in the region, thus obtaining better functional results. ${ }^{14}$ Condyle fractures treated bloodlessly in children present better results, as they still have the capacity for remodelling, unlike adults in which a functional adjustment occurs. However, after fracture of the mandibular condyle in children, there is an excellent chance that the condylar process will regenerate to approximately its original size and a small chance that it will overgrow after injury if adequate function cannot be achieved. ${ }^{15,16}$ The growth potential and remodelling capacity of a condyle during its growth period may be the intrinsic factor for condyle fracture prognosis when treated by closed procedures. ${ }^{9,10}$ To undergo non-surgical treatment, the patient must have good occlusion, absence of displacement of the glenoid cavity, head angulation less than $45^{\circ}$, absent or less than $3 \mathrm{~mm}$ thrust and presence of bone contact, absence of intracapsular foreign body. ${ }^{10}$ The surgery treatment of mandibular condylar fractures results in better mandibular mobility than closed treatment, ${ }^{17}$ but in case noticed hear, the patient showed satisfactory opening, protrusion and lateral excursion and no pain.

For fractures in children, even with displacement, the conservative treatment, which consists of a liquid and pasty diet, with immediate mobilization, presents good results, taking into account the great remodelling capacity of the mandibular condyle. In the case reported here, conservative treatment for the condyle fracture was important, since the patient had already been submitted to an invasive procedure for correction of the symphysis fracture, thus, it was important not to submit her to another traumatic intervention.

In conclusion we can affirm that the adopted protocol proved to be adequate and efficient to ensure the correction of injuries and the restitution of form and function.

\section{Acknowledgments}

None.

\section{Funding}

None.

\section{Conflicts of Interest}

Author declares that there is no conflict of interest.

\section{References}

1. Singh V, Bhagol A, Goel M, et al. Outcomes of open versus closed treatment of mandibular subcondylar fractures: a prospective randomized study. J Oral Maxillofac Surg. 2010;68(6):1304-1309.

2. Asim MA, Ibrahim MW, Javed MU, et al. Functional outcomes of open versus closed treatment of unilateral mandibular condylar fractures. $J$ Ayub Med Coll Abbottabad. 2019;31(01):67-71.

3. Cleveland CN, Kelly A, De Giovanni J, et al. Maxillofacial trauma in children: Association between age and mandibular fracture site. Am J Otolaryngol. 2021;42(2):102874.

4. Zhou HH, Lv K, Yang RT, et al. Mandibular condylar fractures in children and adolescents: 5-Year retrospective cohort study. Int J Pediatr Otorhinolaryngol. 2019;119:113-117.

5. Zhou HH, Ongodia D, Liu Q, et al. Incidence and pattern of maxillofacial fractures in children and adolescents: a 10 years retrospective cohortstudy. Int J Pediatr Otorhinolaryngol. 2013;77(4):494-498.

6. Ghasemzadeh A, Mundinger GS, Swanson EW, et al. Treatment of pediatric condylar fractures: a 20-year experience. Plast Reconstr Surg. 2015;136(6):1279-1288.

7. Vazquez MP, Kadlub N, Soupre V, et al. Plaies et traumatismes de la face de l'enfant. Ann Chir Plast Esthet. 2016;61(5):543-559.

8. Steed MB, Schadel CM. Management of pediatric and adolescent condylar fractures. Atlas Oral Maxillofac Surg Clin North Am. 2017;25(1):75-83.

9. Vincent AG, Ducic Y, Kellman R. Fractures of the Mandibular Condyle. Facial Plastic Surgery. 2019;35(6):623-626.

10. Zide MF, Kent JN. Indications for open reduction of mandibular condyle fractures. J Oral Maxillofac Surg. 1983;41(2):89-98.

11. Goodday RHB. Management of Fractures of the Mandibular Body and Symphysis. Oral Maxillofacial Surg Clin N Am. 2013;25(4):601-616.

12. Villareal PM, Monje F, Junquera LM, et al. Mandibular condyle fractures: determinants of treatment and outcome. J Oral Maxillofac Surg. 2004;62(2):155-163.

13. Snyder SK, Cunningham LL. The biology of open versus closed treatment of condylar fratures. Atlas Oral Maxillofac Surg Clin North Am. 2017;25(1):35-46.

14. Schneider M, Erasmus F, Gerlach KL, et al. Open reduction and internal fixation versus closed treatment and mandibulomaxillary fixation of fractures of the mandibular condylar process: A randomized, prospective, multicenter study with special evaluation of fracture level. Int J Oral Maxillofac Surg. 2008;66(12):2537-2544.

15. Tunal WB, Dündar A, Cankaya AB, et al. Conservative approach to unilateral condylar fracture in a growing patient: a 2.5-year follow up. Open Dent J. 2012;6(1):1-4.

16. Rutges JP, Kruizinga EH, Rosenberg A, et al. Functional result after conservative treatment of mandibular condyle. Br J Oral Maxillofac Surg. 2007;45(1):30-34. 
17. Al Moraissi EA, Ellis E. Surgical Treatment of Adult Mandibular Condylar Fractures Provides Better outcomes than Closed Treatment:
A Systematic Review and Meta-Analysis. J Oral Maxillofac Surg. 2015;73(3):482-493. 